\title{
プラズマアクチュエータを用いた噴流拡散制御の研究 一向心型アクチュエータによる噴流拡散制御一
}

\section{Study of Diffusion control of jet using the centripetal type plasma actuator}

\author{
○宮城 徳誠（日大短大)，大西 真澄(日大院），朝倉 洵 (日大院) \\ 佐用 健太郎(日大院)，金 洪宇(日大院)，木村 元昭(日大理工)
}

\begin{abstract}
Norimasa Miyagi, Nihon University junior collage, Noarashinoda- 7-24-1, Finabashi-city, Chiba, 274-8501
It was attempted to control of jet diffusion of round jet using centripetal type plasma actuator. It was visualized and analyzed by the PIV. It was obtained the following. By driving a steady plasma actuator, the induced flow convergence, has become a jet of volume flow rate $Q=15 \sim 50 \mathrm{~L} / \mathrm{min}$. Induced flow which caused by the ionized area are concentric, the flow velocity becomes faster and boundary layer thickness becomes thicker, as ionized area larger. When applied to a circular jet, the velocity of primary jet becomes faster by the effect of contraction and the momentum of the induced flow. When the ionized area becomes narrower, the effect of contraction by the induced flow is increased.
\end{abstract}

\section{Key Words: Jet, Mixing, Plasma actuator, PIV}

\section{1. 諸言}

本研究では，円形噴流に対して DBD プラズマアクチュ エータを適用するに当たり, ノズル出口垂直面に円形のプラ ズマアクチュエータを与え, 外部からの誘起流れによって円 形噴流に運動量を付加する方式(運動量付加方式, Fig.1 $)^{\eta}$ ) ノズル出口内壁面にプラズマアクチュエータを設置し, 誘起 流れによって噴出する流体運動量を拡散する方式(運動量拡 散方式 $)^{8)}$ と 2 種類の方式を適用している. 本稿では, 運動量 付加方式について取り扱う. 最初に噴流を与えない状態で, 適用したプラズマアクチュエータによる誘起流れの流速と 流量を計測した。次に, 円形噴流に誘起流れを適用した場合 の噴流構造を, 可視化実験と PIV 解析を用いて解析を行った.

\section{2. 実験装置}

Table 1 に同心円型 DBD プラズマアクチュエータの仕様 を示す. DBD プラズマアクチュエータは, 両面に銅コーティ ングした厚さ $125 \mu \mathrm{m}$ のポリイミドシートに対し, 両面に銅 エッチングによりそれぞれ表側(露出側 : exposed electrode)電 極々裏側(被膜側： covered electrode)電極を同心軸上に形成し た. 形成したシートは，ノズル噴出口を塞がないようノズル と同心軸上に貼り付け，DBD プラズマアクチュエータを設 置している.ノズルはアクリル製として, 絶縁しているもの とする.ノズルは直径 $d=10 \mathrm{~mm}$ の等速度ノズルとし, プラズ マアクチュエータの電極は被膜側電極の外径と露出側電極 の内径によって 4 種類とした. 誘起流れは噴流に向かって外 側から内側に流れるように設置している.プラズマアクチュ エータの駆動は, 高電圧電源(PSI 製 PG1040F)より, 印加電 圧 $E=3 \sim 5 \mathrm{kV}$, 周波数 $f=4 \mathrm{kHz} \sim 15 \mathrm{kHz}$ の交流電圧を印加し, プラズマを発生させている. バースト信号などによる周期的 変動は行わず，誘起流れは定常流れとする。

Fig.2 に実験装置を示す，ノズルから噴出する気体に空気 を使用し， $R e=1,000$ となるように, デジタルマスフローコ ントローラで流量を調整した(断面流量 $Q_{0}=7.4 \mathrm{~L} / \mathrm{min}$ 断面流 速 $U_{0}=1.83 \mathrm{~m} / \mathrm{s}$ ). 噴流および誘起流れの可視化のために, ノ ズル噴出部を直径 $300 \mathrm{~mm}$ 高さ $530 \mathrm{~mm}$ の透明アクリル円筒で 覆い, 円筒内に直径 $1 \mu \mathrm{m}$ 程度のシード粒子(オンジナオイル) を充填してから実験を行った. 可視化実験は, 光源を Nd:YAG レーザ(Omicron 製 FK-LA5000:入=532 nm)を用いたレーザラ イトシート法により噴流軸中心上の可視化を行っている. 撮
影にはハイスピードカメラ(Photron 製 FASTCAM SA1.1： flame rate: 6,000fps, 576x1024 pixel )を用い, 噴流の初期領域 $x / d=6$ 程度までの撮影を行う.ここで, $x$ はノズルからの噴出 方向, $y$ を半径方向距離とする.

PIV 解析は西華産業社製の Koncerto II ver.0.3.70 を用いた. 解析は検查領域 32x32pixcel の正方グリッドとし， x,y 方向に 6step(Overlap80\%)ごとずらし, 161x91 の測定点にて解析を行 う. 解析アルゴリズムは初期值 96x96pixl の階層相関法を採 用し, 誤ベクトル除去には，空間バリデーションの最大值・ 分散值・メディアンそれぞれのフィルタを用いて内層補完し
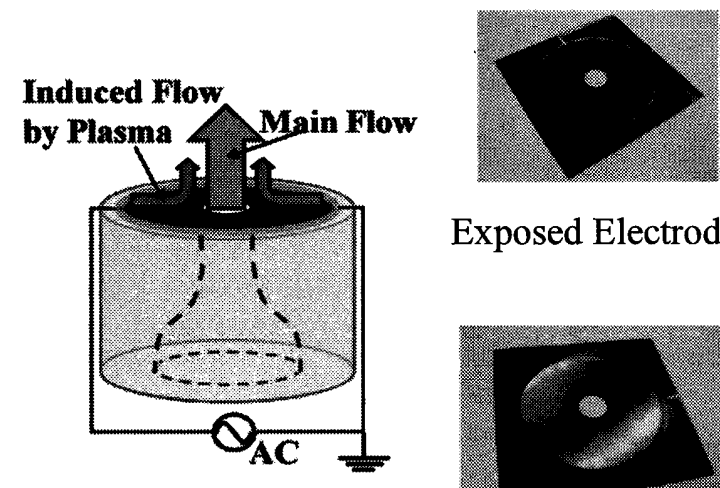

Exposed Electrode

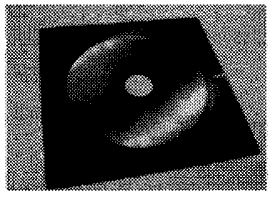

Covered Electrode

Fig.1 Schematic diagram of Plasma actuator to jet control

Table.1 Specific configurations of concentric type Plasma Actuator.

\begin{tabular}{|c|c|c|c|c|c|}
\hline \multirow[b]{2}{*}{ Type } & \multicolumn{2}{|c|}{ Covered Electrode } & \multicolumn{2}{|c|}{ Exposed Electrode } & \multirow[b]{2}{*}{$\begin{array}{c}\text { Ionized Range } \\
y / r\end{array}$} \\
\hline & $\begin{array}{c}\text { Inside } \\
\text { diameter [mm }\end{array}$ & $\begin{array}{c}\text { Outside } \\
\text { Diameter [mm] }\end{array}$ & $\begin{array}{c}\text { Inside } \\
\text { diameter [mm] }\end{array}$ & $\begin{array}{c}\text { Outside } \\
\text { Diameter [mm] }\end{array}$ & \\
\hline (1) Small & \multirow{4}{*}{20} & 30 & 31 & 33 & $2 \sim 3$ \\
\hline (2)Midium_Wide & & 40 & 41 & 45 & $2 \sim 4$ \\
\hline (3) Midium & & 40 & 41 & 43 & $2 \sim 4$ \\
\hline (4) Large & & 60 & 61 & 63 & $2 \sim 6$ \\
\hline
\end{tabular}


ている. 元画像は $6,000 \mathrm{fps}, 200$ コマずつ取得し，解析デー

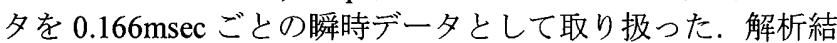
果はその時間平均値としている.

\section{3. 実験結果}

向心型アクチュエータによる誘起流れを，円形噴流 No_PA：噴出直径 $d=10 \mathrm{~mm}$, 噴出流量 $Q=7.8 \mathrm{~L} / \mathrm{min}$, 噴出速 度 $\left.U_{0}=1.85 \mathrm{~m} / \mathrm{s}\right)$ に適用した場合の効果を示す．Fig.3に，各電 極を用いて，プラズマアクチュエータを印加電圧 $E=5 \mathrm{kV}$ ，印 加周波数 $f=12 \mathrm{kHz}$ で駆動した時の PIV 解析した結果を示す. 同図(a)はプラズマアクチュエータを与えていない場合, 同図 (b)は(3)Medium の電極で与えた場合である.これらの図より， プラズマアクチュエータによって, 誘起流れは主噴流に対し て縮流を与える効果となり，主噴流のポテンシャルコア内で の速度が増速させていることがわかる．Fig.4に PIV 解析よ り求められた，誘起流れが収束された， $x / d=3$ における流れ 方向速度分布を示す. 電離層が狭い電極では，ノズル付近で 誘起流れが収束するため, 付加された流量分は中心速度が増 加する，電離層が広い場合は，噴流の幅が広いため, 主流速 度の増加はほかの電極に比べて小さかった。

Fig.5に, PIV 解析によって求められた, 制御された噴流の各 諸量の流れ方向分布を示す. 同図(a)は制御された噴流の各断 面における, 式(1)より求めた体積流量を示寸. 体積流量の増 加を示すため, 主噴流流量 $Q 0$ と誘起流れの流量 $Q i$ の合算値 は $x / d=1$ における体積流量とした. それぞれの電極において， 誘起流れによって体積流量は $(Q 0+Q i) / Q 0$ は(1)Small で 2.3 倍, (2)(3)wide, medium で 3.2 倍, (4)Large で 4.0 倍と増加してい る. 同図(b)は噴流の中心速度 Uc, (c) は運動量厚さ $\theta$ を示す. 今回の解析の範囲 $(x / d=1 \sim 5)$ では，いずれの場合においても， アクチュエータを駆動させない場合に比べて, 誘起流れによ る運動量を付加と縮流の効果により, 中心速度が速くなり, 噴流の幅が広がった. 体積流量 $Q$ は，誘起流れが噴流に収束 して以降，周囲の流体を巻き込むため，徐々に増加していっ た.しかし，電極(4)Large の場合，誘起流れが収束した後で 噴流の幅が狭まるため，体積流量は減少していった，運動量 厚さは, 誘起流れが収束する $x / d=3$ 以降で, 増加していった。

それにしたがって, 体積流量も周囲流体を巻き込む形で増加 していった，しかし，(4)Large の場合，誘起流れにより，幅 の広い噴流が形成されるため, 運動量厚さも全領域で厚い傾 向となった。

\section{4. 結論}

向心型プラズマアクチュエータを用いて, 円形噴流の拡散制 御を試みた。 PIV 解析を行った結果，以下の知見を得た.

円形噴流に適用した場合, 誘起流れが主噴流に与える 縮流効果と誘起流れの運動量により，主噴流の流速が 速くなった。

電離層の範囲が狭くなるほど，誘起流れによる縮流の 効果は大きくなる。

\section{謝辞}

本研究は文部科学省科学研究費補助金(基盤研究(C), 課題番 号：22560176)の支援を受けた。特記して深く感謝の意を表 す

\section{参考文献}

1) Hongyu Jin, Tkashi Ono, Motoaki Kimura, "Jet Flow control by DBD Actuator -Effect of Electrode Dimensions on jet diffusion-", Proceedings of ASME-JSME-KSAME joint conference, AJK2011-25002, (2011)

2）大西真澄，朝倉洵，金洪宇，木村元昭 “同軸型 $\mathrm{DBD} フ ゚ ラ$ ズマアクチュエータを用いた噴流拡散制御”，日本機械 学会 2012 年度年次大会講演会 S056021，(2012)

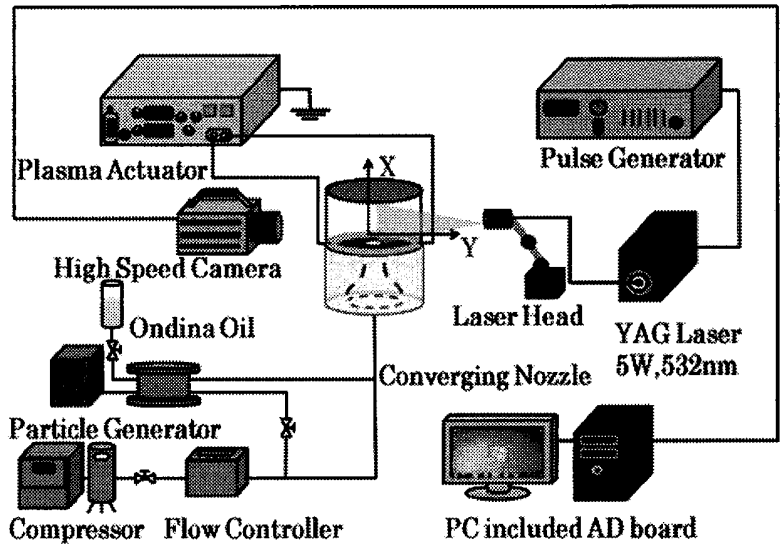

Fig.2 Experimental apparatus

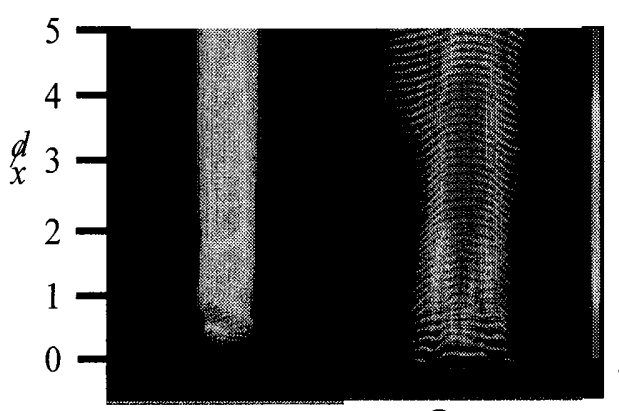

(a) No PA

(b) (3)Medium

Fig.3 PIV analysis result of controlled jet as plasma actuator changing ( $E=5 \mathrm{kV}, f=12 \mathrm{kHz})$.

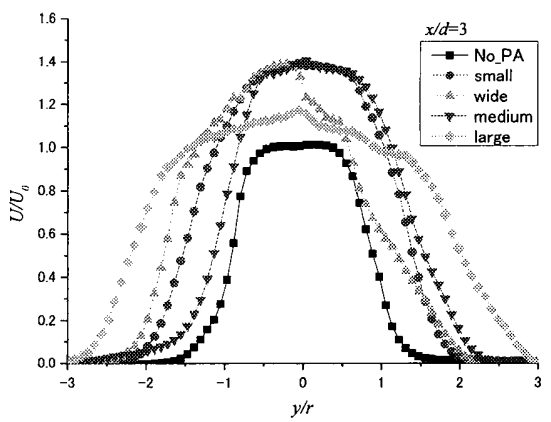

Fig.4 Velocity profile of controlled jet at $x / d=3$.

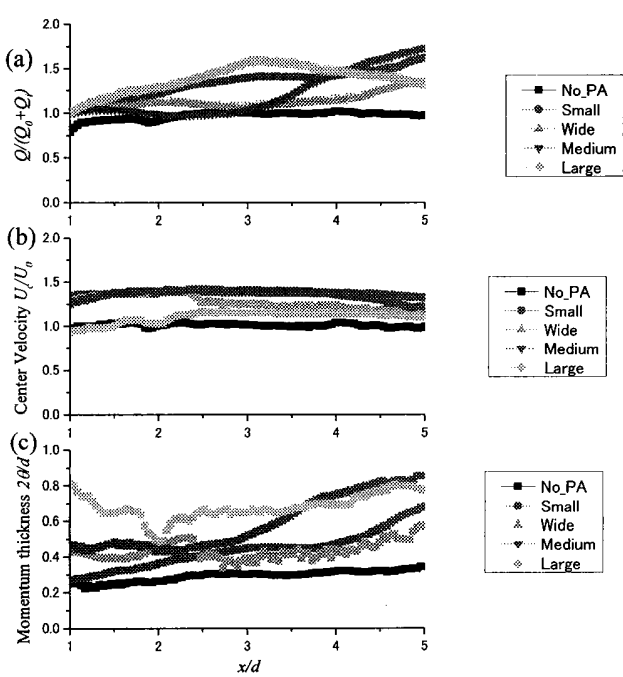

Fig. 5 Properties of controlled jet at $x / d=3$. 